\title{
El debido proceso en las actuaciones administrativas de las fotomultas*
}

\author{
James Orlando Obando Carrascal" \\ Alejandra Ramírez Valencia" \\ Jhonatan Stiven Vergara Franco
}

Recibido: 2 de octubre de 2019 • Aprobado: 28 de noviembre de 2019

\section{Resumen}

En el presente proyecto de investigación se busca observar cómo se están llevando a cabo las notificaciones de fotodetecciones, más conocidas como fotomultas, y establecer si se está vulnerando o no el derecho fundamental al debido proceso administrativo y, por consiguiente, el principio de legitimidad consagrado en el artículo 6 de la Constitución política de Colombia, como consecuencia de esta práctica por parte de los institutos de movilidad del país. Se procede a estudiar de manera juiciosa la jurisprudencia y la doctrina que ayuden a dilucidar de manera clara cómo se garantiza por parte de la administración este derecho fundamental y, por ende, si se cumple con los fines esenciales del estado.

Palabras clave: Actuaciones administrativas. Debido proceso administrativo. Constitución política de 1991. Fotomultas. Jurisprudencia. Notificaciones.

* Este manuscrito es producto del proyecto de investigación: "Desarrollo del debido proceso administrativo en las fotomultas", gestionado en la Fundación Universitaria del Área Andina, sede Pereira, Colombia.

Citar como: Obando Carrascal, J. O., Ramírez Valencia, A. y Vergara Franco, J. S. (2020). El debido proceso en las actuaciones administrativas de las fotomultas. Revista IUSTA, 52, 147-161. DoI: https://doi.org/10.15332/25005286.5487

** Estudiante en décimo semestre de Derecho, Fundación Universitaria del Área Andina, sede Pereira. hobando4@estudiante.arandina.edu.co.orciD: 0000-0001-7403-9491.

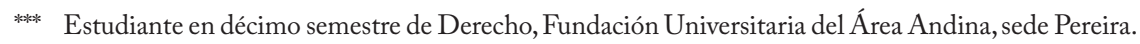
aramirez95@estudiantes.areandina.edu.co.orciD: 0000-0002-3766-5474.

****** Estudiante en décimo semestre de Derecho, Fundación Universitaria del Área Andina, sede Pereira. jvergara13@estudiantes.areandina.edu.co. oRcıD: 0000-0001-6897-7668. 


\title{
THE DUE PROCESS IN THE ADMINISTRATIVE ACTIONS OF CAMERA TICKETS
}

\begin{abstract}
This research project seeks to observe how notifications of traffic camera offences, better known as camera tickets, are made and establish whether or not the fundamental right to administrative due process is being violated and, consequently, the principle of legitimacy stipulated in Article 6 of the Political Constitution of Colombia, as a result of this practice by the country's transportation institutes. The jurisprudence and doctrine that help explain clearly how the administration guarantees this fundamental right is carefully studied and, therefore, if the essential purposes of the state are fulfilled.
\end{abstract}

Keywords: administrative actions, administrative due process, Political Constitution of 1991, camera tickets, jurisprudence, notifications.

\section{O DEVIDO PROCESSO NAS ATUAÇÕES ADMINISTRATIVAS DAS FOTO MULTAS}

\section{Resumo}

Neste projeto de pesquisa busca-se observar como estão se realizando as notificações das foto detecções, mais conhecidas como foto multas e estabelecer se está-se vulnerando ou não o direito fundamental ao devido processo administrativo e, por conseguinte, o princípio de legitimidade consagrado no artigo 6 da Constituição política da Colômbia, como consequência desta prática por parte dos institutos de mobilidade do país. Procede-se ao estudar de maneira rigorosa a jurisprudência e a doutrina que ajudem ao elucidar como se garante por parte da administração este direito fundamental e, portanto, se cumpre com os fins essenciais do estado.

Palavras-chave: atuações administrativas, devido processo administrativo, Constituição política de 1991, foto multas, jurisprudência, notificações. 


\section{Introducción}

El presente trabajo de investigación aborda el tema del debido proceso en las actuaciones administrativas de las fotomultas. Cabe resaltar que Colombia es un Estado social de derecho, donde se busca la máxima protección de los derechos inherentes a los ciudadanos (Blanco, 2013). La Carta Magna y su garantía con los derechos fundamentales se traduce en bienestar social, y el interés general siempre prevalecerá sobre cualquier interés particular (Saidiza y Carvajal, 2016).

Entre muchas de estas garantías constitucionales, se encuentra el artículo 29 de la Constitución política: el derecho al debido proceso. Este es un pilar fundamental e inamovible, sobre el cual descansa todo el sistema jurídico, y debe respetarse en todas las actuaciones administrativas (Blanco y Gómez, 2016).

Por otra parte, a lo largo del presente trabajo, se analizará si la secretaría de tránsito y movilidad sigue las pautas normativas y la regulación, en cada una de las actuaciones administrativas que realiza, como los comparendos por medio de detección electrónico con sistemas automáticos y semiautomáticos, para poder saber si este ente vulnera o no el derecho al debido proceso.

En consecuencia, se pretende dar a conocer cómo funciona el debido proceso en las actuaciones administrativas de las fotomultas, ayudar a identificar cuándo se puede ver amenazado este precepto constitucional y establecer las diferentes herramientas jurídicas para llevar a cabo los procesos adecuados, que tienen como fin garantizar el derecho al debido proceso.

Además, se busca verificar si el fin único del debido proceso es permitir que las personas tengan la oportunidad de ser oídas y hacer valer sus pretensiones. Este es un limitante a las diferentes leyes y procedimientos legales, por lo que los jueces son los encargados de garantizar los principios fundamentales, como la imparcialidad, la justicia y la libertad. Esto ayuda a dilucidar cómo es el funcionamiento de este derecho fundamental dentro de los institutos de movilidad del país (Guarín y Aldana, 2016).

El derecho al debido proceso se ve altamente vulnerado, en muchas situaciones, por falta de conocimiento frente a la notificación. Esta notificación se expide en un acto administrativo definitivo, y es importante aclarar que este acto administrativo definitivo o principal es la declaración unilateral de la voluntad de la administración, mediante la cual se define una situación jurídica (Humbarita, 2015). 
Esto implica necesariamente que los individuos afectados no tengan la oportunidad de interponer los recursos de ley, lo que se traduce en una barrera para ejercer sus derechos a la defensa y contradicción, en cada una de las etapas del proceso administrativo.

Ante todo, como se decía anteriormente, el debido proceso es de gran importancia, es un derecho fundamental enmarcado en el artículo 29 de la Constitución política de Colombia (marca notable de su jerarquía). Sin embargo, no se le presta la atención que requiere. El debido proceso está inmerso en diferentes casos, sin importar el área jurídica.

Además, se centrará la atención en el basto avance jurisprudencial que ha venido surgiendo frente al "debido proceso", en relación al tema de las fotodetecciones, más conocidas como fotomultas. El fin es reflexionar si en Colombia realmente se está vulnerando este derecho fundamental, estipulado en el artículo 29 de la Constitución política de Colombia.

Es menester tener en cuenta que cualquier entidad que desarrolle actividades delegadas por el Estado debe cumplir con un mínimo de requerimientos establecidos por la ley y la Constitución. En el caso concreto, tanto los institutos de movilidad como los contratistas, encargados de la instalación y manejo de todo el sistema electrónico de las fotomultas, deben cumplir con estas exigencias.

Ninguno de ellos tiene la facultad para sobreponerse a las normas establecidas ni a la jurisprudencia, que, como se sabe, funge como una de las fuentes del derecho, y por eso su importancia y relevancia frente al avance social en diferentes áreas. Es por lo anterior que se debe cumplir con el precepto constitucional del debido proceso, estipulado en el artículo 29 de la Carta Magna.

Las fotomultas implementadas en el territorio nacional fueron propuestas como una solución alternativa al alto índice de fatalidad a causa de los excesos de velocidad. Sin embargo, después fueron implementadas otras funciones de control a los vehículos automotores, como es la detección de vehículos con pico y placa, o que no cuentan con el seguro obligatorio y la revisión tecno-mecánica. Aunque es innegable que la utilización de todas estas estrategias implica un avance significativo, en cuanto a la movilidad y prevención vial del país, también ha generado una gran problemática entre la ciudadanía que se ha visto afectada por estos procedimientos administrativos, pues la mayoría solo se enteran de la presunta infracción en el momento de adelantar cualquier diligencia ante los institutos de movilidad. Por esta 
razón, se despierta la curiosidad por conocer si se está aplicando debidamente el derecho al debido proceso, que hace parte del principio de legalidad.

Dentro del marco de legalidad, es acorde mencionar que, desde septiembre de 2018, entró en vigencia la resolución 718 del 2018, que abarca amplia normatividad frente al tema de las fotomultas y establece los parámetros y criterios que tienen que cumplir los medios tecnológicos para la detección de presuntos infractores. Esta resolución da unos estándares de ubicación de cámaras y radares: establece que las cámaras de fotodetección deben ser visibles 500 metros antes de su ubicación en vías nacionales, y así mismo hace referencia a las debidas notificaciones.

De la misma forma, la ley 1843 del 2017 regula la instalación y puesta en marcha de sistemas automáticos, semiautomáticos y otros medios tecnológicos para la detección de infracciones. Este tema ha generado grandes controversias y diferentes puntos de vista, de modo que despertaron el interés suficiente para realizar la presente investigación académica, ya que la resolución y la ley realizaron un trabajo juicioso al desarrollar la normatividad de las fotomultas, pero en la aplicación se han presentado periódicamente diferentes sucesos que desencadenan problemas sociales: inconvenientes con el sistema de notificación, con la ubicación de las cámaras, con la aplicación por parte de las instituciones y el cumplimiento de parámetros.

De acuerdo a lo anterior, se determina realizar el siguiente artículo de reflexión, bajo el enfoque de la pregunta que a continuación se describe: ¿cómo se desarrolla el debido proceso en las actuaciones administrativas de las fotomultas?

Así mismo en el presente trabajo se establecen los siguientes objetivos:

\section{Objetivo general}

Desarrollar el debido proceso en las actuaciones administrativas de las fotomultas.

\section{Objetivos específicos}

- Establecer si se cumple con el debido proceso en las notificaciones de las fotomultas.

- Especificar los términos de prescripción de las fotomultas.

- Determinar si puede existir o no responsabilidad solidaria en los comparendos de las fotomultas. 


\title{
2. Desarrollo de la investigación
}

Es importante abordar el concepto del debido proceso desde diferentes fuentes y perspectivas, la primera será la definición que entrega la honorable Corte Constitucional, en su sentencia C-980 de 2010, donde manifiesta el colegiado como:

\begin{abstract}
El conjunto de garantías previstas en el ordenamiento jurídico, a través de las cuales se busca la protección del individuo incurso en una actuación judicial o administrativa, para que durante su trámite se respeten sus derechos y se logre la aplicación correcta de la justicia. La misma jurisprudencia ha expresado que el respeto al derecho fundamental del debido proceso, le impone a quien asume la dirección de la actuación judicial o administrativa, la obligación de observar, en todos sus actos, el procedimiento previamente establecido en la ley o en los reglamentos.
\end{abstract}

Y tiene como fin "preservar las garantías -derechos y obligaciones- de quienes se encuentran incursos en una relación jurídica, en todos aquellos casos en que la actuación conduzca a la creación, modificación o extinción de un derecho o a la imposición de una sanción”.

Así las cosas, el derecho fundamental del debido proceso se muestra como un límite a las actuaciones del poder público, con lo que se busca garantizar un eficaz derecho a la defensa de los individuos, que se ven inmersos en procesos de la administración pública. Esto, a su vez, cumple con el principal postulado de la Constitución política de Colombia y sus fines esenciales, como la preservación de la convivencia social y la protección de todas las personas residentes en Colombia, en su honra, bienes y demás derechos y libertades públicas (Const., 1991, arts. 1-2).

De igual manera, y en concordancia con la misma Carta Magna, en los artículos 29 y 150 , numerales 1 y 2 , es competencia del legislador regular los diferentes procesos judiciales y administrativos. Además, debe establecer las etapas, oportunidades y formalidades que le sean aplicables a cada uno de los distintos procesos. También es de su competencia establecer los términos para interponer las diferentes acciones y recursos ante las autoridades tanto judiciales como administrativas (Corte Constitucional, sentencia C-980, 2010).

Así, en la sentencia C-341 del año 2014, se ratifica el concepto del debido proceso, y la honorable Corte Constitucional explica los elementos que hacen parte de esta garantía constitucional: 
(i) El derecho a la jurisdicción, que a su vez conlleva los derechos al libre e igualitario acceso a los jueces y autoridades administrativas, a obtener decisiones motivadas, a impugnar las decisiones ante autoridades de jerarquía superior, y al cumplimiento de lo decidido en el fallo; (ii) el derecho al juez natural, identificado como el funcionario con capacidad o aptitud legal para ejercer jurisdicción en determinado proceso o actuación, de acuerdo con la naturaleza de los hechos, la calidad de las personas y la división del trabajo establecida por la Constitución y la ley; (iii) el derecho a la defensa, entendido como el empleo de todos los medios legítimos y adecuados para ser oído y obtener una decisión favorable. De este derecho hacen parte: el derecho al tiempo y a los medios adecuados para la preparación de la defensa, los derechos a la asistencia de un abogado cuando sea necesario, a la igualdad ante la ley procesal, a la buena fe y a la lealtad de todas las demás personas que intervienen en el proceso. (iv) $\mathrm{El}$ derecho a un proceso público, desarrollado dentro de un tiempo razonable, lo cual exige que el proceso o la actuación no se vea sometido a dilaciones injustificadas o inexplicables; (v) el derecho a la independencia del juez, que solo es efectivo cuando los servidores públicos, a los cuales confía la Constitución la tarea de administrar justicia, ejercen funciones separadas de aquellas atribuidas al ejecutivo y al legislativo; y (vi) el derecho a la independencia e imparcialidad del juez o funcionario, quienes siempre deberán decidir con fundamento en los hechos, conforme a los imperativos del orden jurídico, sin designios anticipados ni prevenciones, presiones o influencias ilícitas.

De igual manera, la Procuraduría General de la Nación manifiesta que el derecho al debido proceso se compone no solo de la observancia del proceso que impone la norma a cada uno de los procesos judiciales y los procesos de trámites administrativos, sino también del respeto de todas las formalidades que son propias de cada uno de los juicios.

El nacimiento de este precepto constitucional se encuentra en el derecho anglosajón. El antecedente histórico más significativo se remonta al siglo xI, cuando los hombres presionaron al rey para redactar una constitución de un escrito conocido con el nombre de la Carta Magna, en el año 1215. Esta disponía la prohibición de arrestar, detener, desposeer de la propiedad o de molestar a ningún hombre libre, excepto "en virtud de enjuiciamiento legal de sus pares y por la ley de la tierra". Desde el juego limpio, se exige igualmente un juicio limpio. A partir de entonces, y hasta la fecha, en la tradición correspondiente al Common Law, se ha presentado un desarrollo jurisprudencial y doctrinal bien estricto. 
Para el autor Ramírez (2004),

El debido proceso es el derecho fundamental que tienen todas las personas (naturales y jurídicas) a participar en procedimientos dirigidos por unos sujetos con unas determinadas condiciones y cuyo desarrollo en su forma, en su decisión y en la contradicción de los intervinientes deberá sujetarse a los lineamientos establecidos en las normas jurídicas. Es un derecho fundamental que reclama de procedimientos pluralistas y ampliamente participativos, en los que se asegure la igualdad y un debate que permita la defensa de todos sus participantes. (p. 20)

Uno de los objetivos planteados es establecer si se cumple o no con el derecho fundamental al debido proceso. Después de realizar un vasto recorrido por las normas que regulan todo lo relacionado con las fotodetecciones, más conocidas como fotomultas, se debe establecer que la ley 1843 del año 2017, en su artículo 8, señala que el envío de la notificación de la multa al propietario del vehículo, más la copia del comparendo y sus soportes, se deberá hacer a través de una empresa de correos legalmente constituida, dentro de los tres días hábiles siguientes a la validación del comparendo por parte de la autoridad.

Sin embargo, es importante manifestar que los ciudadanos tienen una percepción negativa frente a la imposición de comparendos por fotomultas, ya que se enteran hasta el momento en el que se disponen a iniciar cualquier trámite ante cualquier instituto de tránsito. En consecuencia, se puede evidenciar, en este primer panorama, una total vulneración del debido proceso, consagrado en el artículo 29 de la Constitución política de Colombia, pues los ciudadanos no están teniendo la oportunidad de participar en ninguna de las etapas procesales, como tampoco de interponer los recursos a los que tienen derecho. Dado que, al momento de la notificación, ya se han agotado todas las instancias del proceso administrativo, es evidente que no se está cumpliendo con los fines esenciales del Estado. La administración actúa de manera desmedida frente a los procesos que competen esta área del derecho administrativo, en uso de su potestad sancionatoria. Es de precisar que, con este proceder, no solo se está vulnerando el derecho al debido proceso, sino también el principio de legalidad constituido en el artículo 6 de la Constitución política de Colombia. Así, se dispone como ejemplo el informe de la personería de Florida Blanca, con fecha del 17 de abril del año 2017, donde fueron impuestos 68.197 comparendos por foto detección, de los cuales fueron revocados 25.658 , el $37 \%$, por falencias en los diferentes procesos de aplicación de las sanciones. 
Es menester identificar plenamente al infractor. En el presente caso, una fotomulta no cumple con esta exigencia, puesto que no es posible, por este medio, llegar a identificar plenamente a una persona. Así lo manifiesta la Corte Constitucional, diciendo que, "La obligación de cancelar la multa solo tendrá lugar como consecuencia de su vinculación formal a la actuación administrativa, y luego de que se establezca plenamente su culpabilidad en la infracción." (Corte Constitucional, sentencia C-980, 2010).

Por lo anterior, no se puede asegurar que sí se incurrió en una contravención, por el solo hecho de ser notificados. A esto se suma lo siguiente: "Solo se paga la multa cuando se pruebe que fue él quien cometió la infracción, o cuando lo admita expresa o implícitamente" (Corte Constitucional, sentencia C-980, 2010).

Si el fin único del debido proceso es salvaguardar a los ciudadanos de cualquier actuación irregular por parte de la administración, si su propósito principal es establecer unos límites bien definidos a las instituciones representativas del Estado, pero además cumplir con los fines esenciales del Estado y, aún más importante, proteger un derecho de calificación fundamental, que hace parte de la supremacía normativa, entonces no es osado aseverar que nos encontramos frente a una actuación administrativa que está vulnerando no solo el derecho al debido proceso, reconocido en el artículo 29 de la Constitución, sino también el principio de legalidad que es intrínseco a este.

De ninguna manera se está garantizada la participación de los individuos dentro de los procesos adelantados por la administración pública, que al parecer no está cumpliendo con los límites establecidos por la Constitución y las leyes, pues es de conocimiento general que, en la gran mayoría de casos, no cumple con los tiempos estipulados para las debidas notificaciones y citaciones para que se comparezca al proceso. Esto no significa que, en muchos lugares del territorio nacional, no se cumpla con la señalización requerida cuando exista una fotomulta; donde la norma estipula que debe haber señalización 250 metros antes en vías secundarias (local urbana), 500 metros antes en vías principales (arterial urbana) y 1500 metros antes en carretera, según lo avala la resolución No. 0000718 del 22 de marzo del año 2018. Como se mencionó anteriormente, esta estipulación no se está cumpliendo en todo el territorio colombiano, lo que lleva a cuestionar si se cumple realmente con el objetivo principal, es decir, reducir las altas tasas de mortalidad por accidentes de tránsito, o si simplemente es un filtro más de corrupción, por parte de particulares que buscan acrecentar sus patrimonios con apoyo del estado. 


\section{Metodología}

Las investigaciones se construyen dependiendo de las necesidades que se tengan respecto a un tema (Tirado, Bedoya y Blanco, 2016). El presente trabajo se desarrolló bajo parámetros de tipo cualitativo, ya que Martínez (2011) dice que este método: "abarca procesos en términos descriptivos y también interpreta acciones, lenguajes y hechos funcionalmente relevantes, que sitúa en una correlación con un amplio contexto social" (p. 11).

Es descriptiva, ya que pretende indagar sobre el desarrollo normativo y jurisprudencial del debido proceso, en las actuaciones administrativas de las fotomultas. Y es hermenéutico, porque se extraen los criterios establecidos a través de un esfuerzo de interpretación, con base en conceptos de las altas cortes.

La revisión documental que el grupo de investigación ha efectuado resulta necesaria para cumplir con los objetivos propuestos, toda vez que en la misma se establecen los fundamentos normativos, legales y jurisprudenciales del tema bajo estudio, así como la regulación de los mecanismos y la puesta en marcha de los sistemas tecnológicos para la imposición de sanciones pecuniarias (fotomultas). De este modo, la anterior recopilación ayudará en la investigación para conocer la garantía del derecho fundamental al debido proceso en las actuaciones administrativas (publicaciones, notificaciones, derechos a la defensa, contradicción), conocer las obligaciones que tienen las autoridades administrativas para con los coasociados $\mathrm{y}$, en caso de existir irregularidades, ejercer de manera efectiva las acciones necesarias en aras de proteger los derechos de los administrados en sus relaciones con el Estado.

Por lo tanto, la técnica que será utilizada, para el desarrollo del presente trabajo, consiste en la revisión documental de sentencias de las altas cortes, como de los conceptos y resoluciones por parte del Ministerio de Transporte, y, por último, de las normas establecidas en torno a las fotomultas.

Para determinar si existe o no responsabilidad solidaria en los comparendos de fotomultas impuestas por las autoridades administrativas, y así responder al objetivo específico planteado, es pertinente traer a colación la decisión proferida por la Corte Constitucional, en sentencia C-112 de 2018, con ponencia del Dr. José Fernando Reyes Cuartas, en la cual los accionantes pretenden que se declare inexequible el parágrafo 1 del artículo 8 de la ley 1843 de 2017, por medio de la cual se regula la instalación y sistemas automáticos, semiautomáticos y otros medios tecnológicos para la detección de infracciones de tránsito. 
Dicha disposición legal establece que, ante la consumación de una contravención o infracción de tránsito, la persona que figure como propietaria del vehículo será solidariamente responsable con el conductor, a través de la respectiva notificación del comparendo, para que el propietario pueda ejercer su derecho fundamental y constitucional a la defensa. Es menester hacer referencia a los argumentos de los demandantes, ya que en ellos se funda el problema jurídico resuelto por la alta corporación. En este orden, los accionantes sostienen y deprecan la declaratoria de inexequibilidad del apartado en estudio, bajo la tesis de que las autoridades administrativas, al momento de la imposición de los comparendos y al establecer la responsabilidad solidaria del infractor y el propietario del vehículo, desconocen el artículo 29 de la Constitución nacional, por la carga que se le impone al titular del bien de responder por una transgresión cometida por otra persona, y viola la prohibición de auto incriminarse. A su juicio, la norma impone una responsabilidad objetiva, cuando lo que se debería demostrar, por parte de las autoridades, es una responsabilidad de tipo subjetiva, donde exista certeza de la persona que cometió la infracción. Del mismo modo, el Estado colombiano, a través de la potestad sancionatoria, le asiste la carga probatoria. En este sentido, es el Estado, a través de sus autoridades, quien debe demostrar la culpabilidad del infractor, ya que sería inadmisible que el propietario, siendo la parte más indefensa, tenga la obligación de probar que no cometió la infracción de tránsito.

Así pues, en las intervenciones del caso, cabe resaltar la efectuada por la Procuraduría General de la Nación, donde conceptúa y recomienda a la Corte Constitucional declarar que el régimen de responsabilidad ejercido en la imposición de comparendos es inconstitucional, toda vez que las autoridades administrativas deben respetar la presunción de inocencia y, como mínimo, deben individualizar e identificar al transgresor de la norma de tránsito.

Esta previsión de régimen de responsabilidad, garantiza a la administración hacer exigible una obligación a su favor, como es la imposición de la infracción y los derechos pecuniarios que se derivan de ella, empero no es el procedimiento idóneo, pues, como lo señalo el Ministerio Público en su intervención, con la imposición de comparendos en sistemas semiautomáticos y medios tecnológicos no es posible la identificación de la persona que incurrió en la vulneración de la norma de tránsito. Esto ocasiona que la administración persiga el pago por un acto ajeno.

Cabe anotar que la jurisprudencia constitucional, con respecto a la previsión de la responsabilidad solidaria, ha sostenido que las autoridades administrativas, 
al momento de ejercer la potestad sancionatoria y exigir a sujetos distintos del principal obligado (infractor), desconoce flagrantemente el sistema punitivo, basado en que cada persona debe responder por su propios actos y en ningún caso puede sustentarse que, por motivos de interés público, pueda establecerse la responsabilidad solidaria por actos ajenos (Pardo, 2014).

Ahora bien, la alta corporación judicial decidió declararse inhibida para expedir una decisión de fondo sobre el tema puesto a su consideración, ya que los argumentos de los actores no lograron superar los presupuestos exigidos para la procedencia de la demanda de inconstitucionalidad (claridad, certeza, especificidad, pertinencia y suficiencia). Estos son requisitos mínimos indispensables para el estudio de fondo de las acciones impetradas (Rodríguez, 2014). Con lo anterior, se colige que queda incólume la responsabilidad solidaria en las imposiciones de comparendos detectados por fotomulta, debido a que, al soslayarse la alta corporación y no emitir una decisión de fondo, los efectos jurídicos del parágrafo 1 del artículo 8 de la ley 1853 de 2017 siguen siendo exigibles y vinculantes en el ordenamiento jurídico. Por consiguiente, la obligación solidaria, entre propietario del vehículo como infractor de las normas de tránsito, se mantiene ligada en el transcurso de los procesos que se adelanten en sede administrativa ante las autoridades competentes (Corte Constitucional, sentencia C-112, 2018).

Por otra parte, algo que ha generado un vacío importante en los ciudadanos que han incurrido en infracciones de tránsito es lo atinente a las notificaciones de los comparendos (Patarroyo y Benavides, 2014). De modo que la Corte Constitucional, en sede de revisión de tutela, examina la presunta vulneración al debido proceso administrativo, el cual fuera violentado por la autoridad al notificar de manera indebida y extemporánea un comparendo, e imponer la sanción correspondiente. Luego, se procede a determinar que es posible la interposición de la acción de tutela de manera excepcional contra actos administrativos. Si bien en sede administrativa la persona inmersa en la actuación ante las autoridades está legitimada para interponer los recursos que la ley establece; si se surte de manera indebida la notificación de la actuación y comparendo, se considera violentado el debido proceso, resulta procedente la tutela contra los actos mencionados y se debe validar los siguientes criterios:

Respecto del requisito de inmediatez, se debe evaluar criterios como: (i) la existencia de razones válidas para la inactividad, (ii) cuando a pesar del paso del tiempo es evidente que la amenazada o vulneración de los derechos fundamentales 
del accionante permanece y (iii) cuando la carga de la interposición de la acción de tutela en un plazo razonable resulta desproporcionada por la situación de debilidad manifiesta del accionante.

Resulta importante resaltar que, cuando el afectado no cuente con otro medio de defensa judicial, se considera pertinente, de cara al requisito de inmediatez, tener en cuenta (i) la fecha en que se profirió el acto administrativo, (ii) la fecha en que se tuvo conocimiento del mismo y (iii) las acciones desplegadas por la actora desde ese momento (Corte Constitucional, sentencia T-051, 2016).

Finalmente, para la alta corporación, el derecho fundamental al debido proceso se ve violentado cuando la administración notifica de manera indebida a los administrados. De modo que per se constituye una limitación para el normal ejercicio del derecho de defensa, contradicción y publicidad en el procedimiento administrativo (Guarín, 2013). En dado caso, se debe tutelar el derecho fundamental al debido proceso, a través de un mecanismo idóneo como la acción de tutela; mientras que, cuando no se evidencia la vulneración del debido proceso por la notificación del comparendo (acto administrativo), el infractor debe recurrir y hacer uso de los mecanismos y recursos existentes en la ley, conforme a las actuaciones administrativas, y en su defecto recurrir a la jurisdicción contenciosa a través de los diferentes medios de control.

\section{Conclusiones}

1. Cuando los comparendos o multas de tránsito no son notificados personalmente, sino por medios electrónicos, se vulnera el derecho a la defensa y el derecho al debido proceso.

2. E1 Estado, a través de sus autoridades y por medio de la facultad o potestad sancionatoria, no puede desconocer el sistema punitivo, es decir, el ius puniendi que le asiste. De modo que las autoridades, al momento de interponer los respectivos comparendos, deben individualizar e identificar al infractor, y así ajustar lo anterior al régimen de responsabilidad subjetiva, y no objetiva como se da en la actualidad.

3. Es viable reflexionar si realmente el sistema de fotodetección está cumpliendo con el objetivo planteado, el cual es reducir los índices de mortalidad accidental; o si simplemente es un filtro de corrupción de unos particulares con la ayuda del Estado. 


\section{Referencias}

Blanco, C. (2013). Aproximación a la noción de soberanía estatal en el marco del proceso andino de integración. Revista Republicana, 15, 91-103. Recuperado de http://ojs.urepublicana.edu.co/index.php/revistarepublicana/article/view/23/21

Blanco, C. y Gómez, D. (2016). Constitución política e integración andina desde las nociones de soberanía y democracia. En Perspectivas críticas del derecho constitucional colombiano (pp. 56-69). Bogotá, Colombia: Universidad Libre.

Constitución política de Colombia [Const.]. (1991).

Corte Constitucional. (10 de febrero de 2016). Sentencia T-051 del 2016. [Mp. Gabriel Eduardo Mendoza Martelo]. Recuperado de http://www.corteconstitucional.gov.co/ relatoria/2016/t-051-16.htm

Corte Constitucional. (1 de diciembre de 2010). Sentencia C-980 del 2010. [M.P. Gabriel Eduardo Mendoza Martelo]. Recuperado de https://www.corteconstitucional.gov.co/ relatoria/2010/c-980-10.htm

Corte Constitucional. (4 de junio de 2014). Sentencia C-341 del 2014. [M.P. Mauricio Gonzalez Cuervo]. Recuperado de https://www.corteconstitucional.gov.co/ relatoria/2014/C-341-14.htm

Corte Constitucional. (7 de noviembre de 2018). Sentencia C-112 del 2018. [MP. José Fernando Reyes Cuartas]. Recuperado de http://www.corteconstitucional.gov.co/ relatoria/2018/C-112-18.htm

Guarín, E. (2013). Persona y realización efectiva de derechos. Revista IUSTA, 38(1), 133-154.

Guarín, E. A. y Aldana, J. (2016). Estado jurisdiccional y bien común. Revista Verba Iuris, 11(36), 13-26.

Humbarita, J. (2015). Derecho constitucional hispanoamericano frente a la realidad institucional, manifiesta divergencia. Revista IUSTA, 43(2), 34-67.

Martínez, J.(2011). Métodos de investigación cualitativa. recuperado de http://www.cide. edu.co/doc/investigacion/3.\%20metodos\%20de\%20investigacion.pdf

Pardo, N. (2014). Un recorrido por los derechos colectivos en la jurisprudencia argentina. Revista Via Inveniendi et Iudicandi, 9(1), 32-49. Recuperado de http://revistas.usantotomas.edu.co/index.php/viei/article/view/1338/1540 
Patarroyo, S. y Benavides, P. (2014). Rupturas asignificantes: Revisiones críticas en torno al derecho. Revista Via Inveniendi et Iudicandi, 9(1), 7-31.

Personería municipal de Florida Blanca. (17 de abril de 2017). Función preventiva. Recuperado http://personeriadefloridablanca.gov.co/download/funcion_preventiva_2017/VULNERACION-AL-DEBIDO-PROCESO-EN-NOTIF-ICACIONDE-COMPARENDOS-ELECTRONICOS_2.pdf

Procuraduría General de la Nación. (s.f.). Derecho al debido proceso. Recuperado de https://www.mineducacion.gov.co/1759/articles-114277_archivo_ppt4.pdf

Ramírez, J. (2004). El debido proceso. Recuperado de file:///Users/Fabiola/Downloads/ Dialnet-ElDebidoProceso-5238000.pdf

Rodríguez, A. (2014). Indicadores de constitucionalidad de las políticas públicas: enfoque de gestión de derechos. Revista Via Inveniendi et Iudicandi, 9(2), 45-68.

Saidiza, H. y Carvajal, J. (2016). Crisis del Estado de derecho en Colombia: un análisis desde la perspectiva de la legislación penal. Revista IUSTA, 44(1), 17-39.

Tirado, M., Bedoya, J. y Blanco, A. (2016). Bioética y Transhumanidad: Hacia una aproximación al consumo de sustancias nootropicas en el campo académico. En Bioética y Docencia (pp. 91-119). Bogotá, Colombia: Editorial Ibáñez. Recuperado de https://repository.usta.edu.co/handle/11634/1527 